\title{
$\mathrm{DCSK}$ 와 CDSK 방식을 사용하는 카오스 통신 시스템의 항재밍 특성
}

\section{Anti-Jamming Performance of Chaos Communications System Using DCSK and CDSK Modulation Method}

\author{
이 준 현 $\cdot$ 유 흥 균 \\ Jun-Hyun Lee $\cdot$ Heung-Gyoon Ryu \\ 요 약
}

디지털 통신 기술은 보다 높은 데이터 효율과 정보의 효율적인 부호화에 초점을 맞추고 있다. 또한, 보안성을 높이고 외부 요인의 간섭을 최소화하는 것이 중요하다. DCSK(Differential Chaos Shift Keying)나 CDSK(Correlation Delay Shift Keying)와 같은 비선형 시스템에서는 정보를 효율적으로 부호화하여 보안성을 높이고 외부 요인 의 간섭을 최소화시키는 방법으로 카오스 통신 시스템을 많이 사용하고 있다. 본 논문에서는 DCSK 방식과 CDSK 방식에 카오스 맵을 적용하여 카오스 통신 시스템의 BER 성능과 정보의 항재밍 특성을 평가한다. 시뮬레 이션을 통해 Gauss iterated map이 다른 3개의 카오스 맵보다 좋은 성능을 얻을 수 있다는 것을 알 수 있다. 또한, DCSK 방식과 CDSK 방식은 카오스 맵을 적용함으로써 더 좋은 항재밍 특성을 얻을 수 있다.

\section{Abstract}

Digital communication technology have been focused on the higher data efficiency and the effective coding of information. Also, it is very important to improve security and minimize the interference of the external sources, Chaos communications system is studied to improve security and minimize the interference by effective encoding of information in the nonlinear systems such as DCSK(Differential Chaos Shift Keying) and CDSK(Correlation Delay Shift Keying). In this paper, we evaluate anti-jamming performance of chaos communications system using the DCSK and CDSK system. The simulation results show that the Gauss iterated map has better BER performance than the other maps(tent map, logistic map, Henon map). Also, DCSK and CDSK system can get the better anti-jamming performance by applying different chaotic maps.

Key words : DCSK, CDSK, Chaotic Map, Tent Map, Logistic Map, Henon Map, Gauss Iterated Map

\section{I. 서 론}

카오스 이론은 겉으로 보기에는 불안정하고 불규 칙적으로 보이면서도 나름대로 질서와 규칙성을 지
니고 있는 현상들을 설명하려는 이론이다 ${ }^{[1]}$. 이것은 작은 변화가 예측할 수 없는 엄청난 결과를 낳는 것 처럼 안정적으로 보이면서도 안정적이지 않고, 안정 적이지 않은 것처럼 보이면서도 안정적인 여러 현상

\footnotetext{
「이 논문은 2012년도 정부(교육과학기술부)의 재원으로 한국연구재단의 지원을 받아 수행된 기초연구사업임(No. 2012017339).」 충북대학교 전자공학과(Department of Electronics and Engineering, Chungbuk National University)

- Manuscript received January, 3, 2013 ; Revised March 8, 2013 ; Accepted March 12, 2013. (ID No. 20130103-005)

- Corresponding Author : Heung-Gyoon Ryu (e-mail : ecomm@cbu.ac.kr)
} 
을 설명하려는 이론이다.

기존의 디지털 통신 기술에는 성능을 지속적으로 개선하기 위하여 선형 시스템 이론과 필수적으로 선 형성을 이용하였으며, 비선형 시스템은 선형 시스템 의 특정한 수준을 달성하기 위하여 선형화하여 사용 하였다. 하지만 이 기술이 기본적인 한계에 도달함 으로써 비선형 시스템에 카오스 통신 시스템을 적용 하여 비선형적인 통신 시스템의 성능을 개선하기 시 작하였다 ${ }^{[2],[3]}$.

카오스 변조 시스템은 비주기성, 광대역성, 신호 의 비예측성과 같은 특징을 가지며, 이러한 특징으 로 인해 초기 조건에 매우 민감하다. 즉, 카오스 신 호는 카오스 신호 생성기에서 사용된 카오스 맵의 종류와 방정식, 초기 조건에 의해 결정된다. 따라서 초기 조건을 정확히 알아야만 정확한 정보 신호를 예측할 수 있으며, 만약 초기 조건을 알지 못하면 정 보 신호를 정확하게 예측하기가 어렵다.

카오스 신호의 특징을 디지털 통신 기술에 접목 시킴으로써 다른 사용자의 신호의 감지를 어렵게 하 며, 전파 방해나 다중 경로 간섭에 강한 특징을 갖게 하며, 도청 확률을 줄일 수 있기 때문에 보안성을 향 상시킬 수 있다 ${ }^{[4] \sim[6]}$.

이러한 카오스 신호의 특성으로 인해 '카오스 이 론을 이용한 암호화 기법'이나 '이산화된 카오스 함 수를 이용한 새로운 경량의 암호 시스템', '카오스 암호화 알고리즘을 이용한 보안 시스템 설계 및 구 현'과 같은 특정 정보에 대한 암호화 시스템이나 보 안 시스템에 카오스 신호를 적용시키는 연구가 지속 적으로 진행되고 있다.

통신 시스템의 보안성을 평가하는 또 하나의 중 요한 요소로는 재밍 신호에 얼마나 강한 특성을 가 지고 있는지 판단하는 항재밍 특성이 있다 ${ }^{[7],[8]}$. 따라 서 본 논문에서는 기존 카오스 통신 시스템들의 항 재밍 특성에 대한 분석을 진행한다. 항재밍 특성을 평가함으로써 카오스 통신 시스템의 보안성을 평가 할 수 있다.

본 논문에서는 카오스 통신 시스템의 항재밍 특 성 분석을 위하여 재밍 환경에서 차동 카오스 편이 변조(Differential Chaos Shift Keying: DCSK) 변조 방 식과 상관 지연 편이 변조(Correlation Delay Shift Keying: $\mathrm{CDSK}$ ) 변조 방식의 수신 BER 성능을 분석한다.
카오스 방정식은 Tent map, Logistic map, Henon map, Gauss iterated map을 사용하였다 ${ }^{[9],[10]}$.

본 논문의 구성은 다음과 같다. 2장에서는 DCSK 방식과 $\mathrm{CDSK}$ 방식, 그리고 이 시스템에 적용되는 Chaotic Map에 대해서 정의한다. 3장에서는 각 Chaotic Map에 대한 BER 성능을 평가하고, DCSK, CDSK 방식에 적용하여 항재밍 특성에 대해 평가한다.

\section{II. 카오스 시스템의 개요}

이번 장에서는 $\mathrm{DCSK}$ 와 $\mathrm{CDSK}$ 시스템을 정의하 고, 본 연구에 사용된 카오스 방정식에 대한 이론을 서술한다.

\section{2-1 DCSK(Differential Chaos Shift Keying)}

그림 1은 DCSK 방식의 송신기를 나타낸 것이다. 송신기의 카오스 신호 발생기에서 카오스 신호가 출 력되며, 출력된 카오스 신호는 $M$ 만큼 지연된 $\left(x_{i-M}\right)$ 후에 정보 신호인 $b_{i}= \pm 1$ 에 의해 곱해진다. 곱해진 신호와 발생기에서 출력된 신호는 $b_{i}= \pm 1$ 에 의해 곱해진 동일한 순차에 의해 이어진다. 이러한 결과 로 송신기에서 출력되는 송신 신호 $\left(s_{i}\right)$ 는 식 (1)로 나 타난다.

$$
s_{i}= \begin{cases}x_{i} & 0<i \leq M \\ b_{i} x_{i-M} & M<i \leq 2 M\end{cases}
$$

식 (1)의 $M$ 은 지연된 시간을 의미하며, $M$ 을 주기 로 카오스 신호 $\left(x_{i}\right)$ 와 정보 신호 $\left(b_{i}\right)$ 가 곱해진 딜레 이 된 카오스 신호 $\left(b_{i} x_{i-M}\right)$ 가 순차적으로 출력된다.

그림 2는 DCSK 방식의 수신기를 나타낸 것이다. 수신기에서 수신된 신호 $\left(r_{i}\right)$ 를 복구하는 과정은 다 음과 같다. 수신된 신호 $\left(r_{i}\right)$ 와 $M$ 만큼 지연된 수신 된 신호 $\left(r_{i+M}\right)$ 을 곱한 후에 $M$ 만큼 더한다. 그 후 Threshold 값에 따라서 정보 신호 $\left(b_{i}\right)$ 가 복구되며, 이

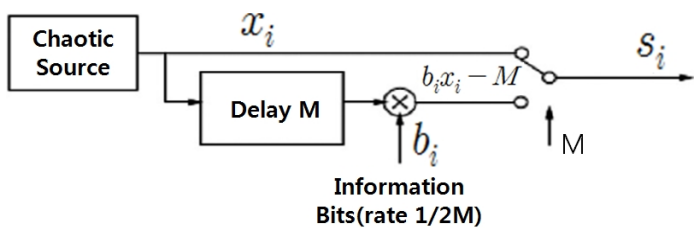

그림 1. DCSK 방식의 송신기

Fig. 1. Transmitter of DCSK system. 


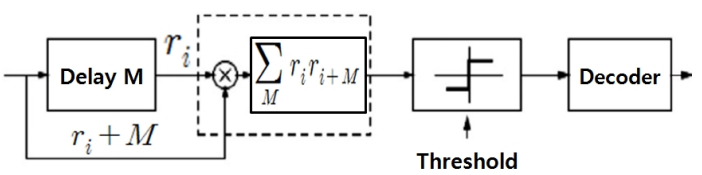

그림 2. DCSK 방식의 수신기

Fig. 2. Receiver of DCSK system.

에 대한 수식은 식 (2)와 같다.

$$
S=\sum_{i=1}^{M} r_{i} r_{i+M}
$$

DCSK 방식의 수신기에서는 지연이 확산 순차 길 이와 동일하다. 따라서 식 (2)의 $M$ 은 송신기와 마찬 가지로 지연된 시간을 의미하는 동시에 확산인자 (Spreading Factor: SF)의 길이를 의미한다.

\section{2-2 CDSK(Correlation Delay Shift Keying)}

$\mathrm{DCSK}$ 의 송신기 출력에서 길이 $M$ 의 카오스 순차 $x_{i}$ 는 정보신호에 의해 곱해진 동일한 순차에 의해 이어지므로 두 번 전송이 필요하다. 이 방법의 단점 은 시스템에서 전력 낭비와 도청의 가능성이 있다는 점이다. 또한, 송신기는 지연요소와 스위치 또는 동 일한 카오스 순차를 재생성할 수 있는 발생기를 요 구한다. 이러한 문제점으로 인하여 제안된 기법이 CDSK이다 ${ }^{[11]}$.

$\mathrm{CDSK}$ 는 $\mathrm{DCSK}$ 의 송신기에 있는 스위치를 가산 기로 대체한 시스템이며, 송신된 신호는 결코 반복 하지 않는 문제점을 극복한 카오스 기반 변조 시스 템이다.

그림 3은 $\mathrm{CDSK}$ 방식의 송신기를 나타낸 것이다. 송신기는 카오스 신호 발생기에서 카오스 신호가 출 력되며, 출력된 카오스 신호는 $L$ 만큼 지연된 $\left(x_{i-L}\right)$ 후에 정보 신호인 $b_{i}= \pm 1$ 에 의해 곱해지는데, 이 과

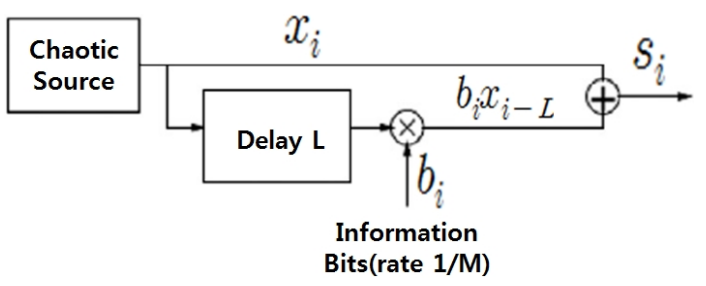

그림 3. $\operatorname{CDSK}$ 방식의 송신기

Fig. 3. Transmitter of CDSK system.

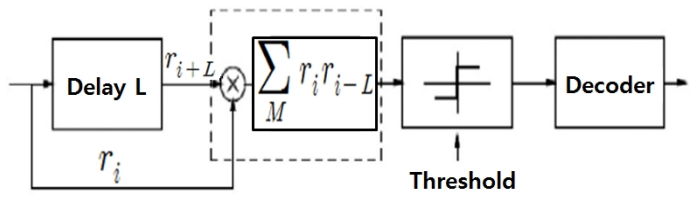

그림 4. CDSK 방식의 수신기

Fig. 4. Receiver of CDSK system.

정은 DCSK 방식과 동일하다. 하지만 $b_{i}= \pm 1$ 에 의 해 곱해진 동일한 순차에 의해 이어지는 것이 아닌 동일한 순차의 합으로 송신 신호 $\left(s_{i}\right)$ 가 생성된다. 이 러한 결과로 송신기에서 출력되는 송신 신호 $\left(s_{i}\right)$ 는 식 (3)으로 나타난다.

$$
s_{i}=x_{i}+b_{i} x_{i-L}
$$

식 (3)의 $L$ 은 지연된 시간을 의미하며, DCSK의 문제점을 해결함으로써 송신기를 보다 간단하게 만 들 수 있다.

그림 4는 CDSK 방식의 수신기를 나타낸다. CDSK 방식의 수신기는 DCSK 방식의 수신기와 동일하 게 구성되어 있으나, 지연이 확산 순차 길이와 동일 하지 않다는 차이점이 있다.

$$
S=\sum_{i=1}^{M} r_{i} r_{i-L}
$$

식 (4)는 $\mathrm{CDSK}$ 의 수신기를 수식으로 나타낸 것이 며, $L$ 은 지연된 시간을 의미하고, $M$ 은 확산인자를 의미한다.

\section{2-3 Chaotic Map}

\section{2-3-1 Tent Map}

$$
x_{n+1}=\alpha|0.5-| 0.5-x_{n}||
$$

Tent map의 방정식은 식 (5)로 표현되며, Tent map 방정식에서 $\alpha$ 값을 1.99999로 설정했을 때, 그림 5 와 같은 궤적을 그린다.

Tent map 궤적의 $\mathrm{x}$ 축은 $x_{n}$ 이며, $\mathrm{y}$ 축은 $x_{n+1}$ 이다. 즉, 현재의 입력으로 이전의 출력 값을 사용하는 비 선형적인 특징을 가진다. 이득 $\alpha$ 의 값이 1.01 보다 작으면 선형적인 특징을 가지며, 이득의 값이 증가 할수록 출력의 궤적은 더 큰 폭으로 변화한다. 


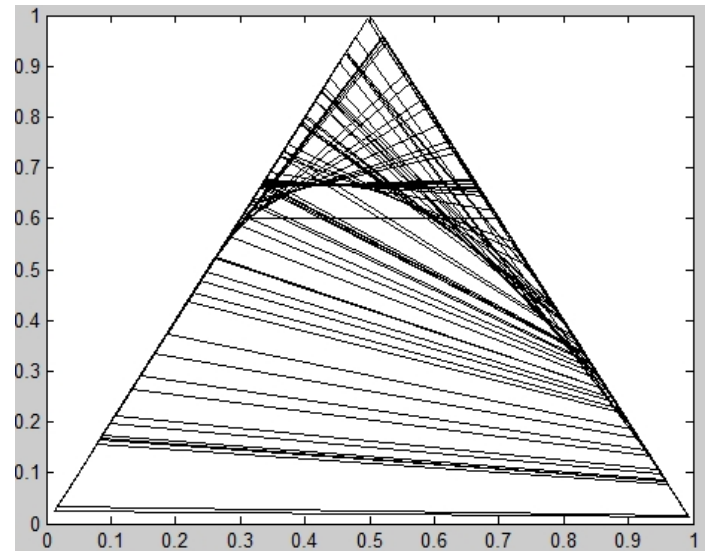

그림 5. Tent map의 궤적

Fig. 5. The trajectory of Tent map.

\section{2-3-2 Logistic Map}

$$
x_{n+1}=R x_{n}\left(1-x_{n}\right)
$$

Logistic map의 방정식은 식 (6)으로 표현되며, Logistic map 방정식에서 $R$ 값을 3.9999로 설정했을 때, 그림 6 과 같은 궤적을 그린다.

Logistic map 궤적의 $\mathrm{x}$ 축은 $x_{n}$ 이며, $\mathrm{y}$ 축은 $x_{n+1}$ 이 며, 이전의 출력 값을 입력으로 사용한다. Logistic map은 개체가 환경적인 요소에 의해서 독립적으로 증가할 수 없고, 보통 포화되거나 발진하기 때문에 선형적인 특성만을 가지지 않는다.

\section{2-3-3 Henon Map}

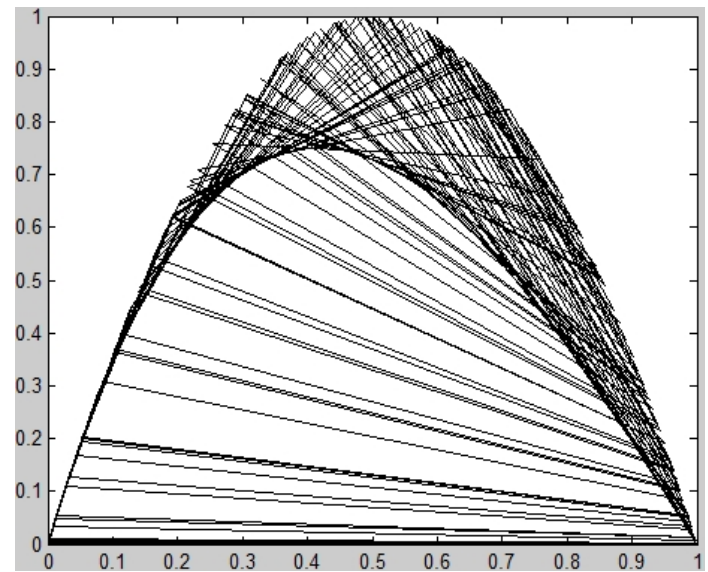

그림 6. Logistic map의 궤적

Fig. 6. The trajectory of Logistic map.

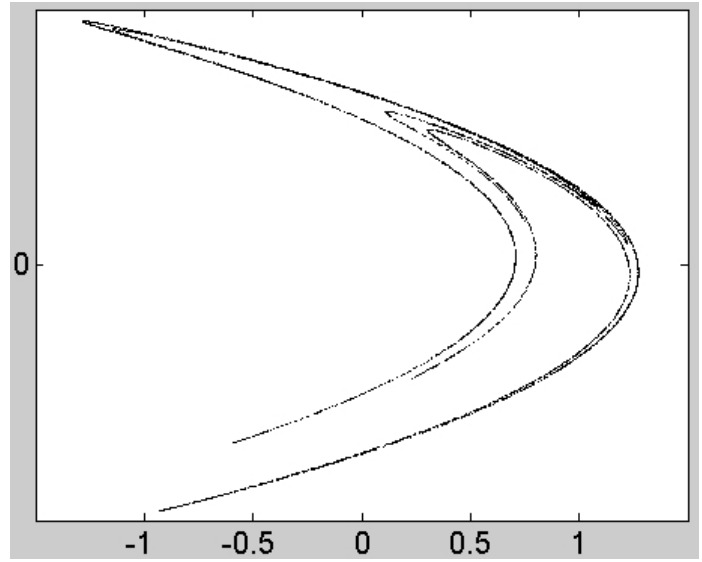

그림 7. Henon map의 궤적

Fig. 7. The trajectory of Henon map.

$$
\begin{aligned}
& x_{n+1}=1+y_{n}-a\left(x_{n}\right)^{2} \\
& y_{n+1}=b x_{n}
\end{aligned}
$$

Henon map의 방정식은 식 (7)로 표현되며, 표준 Henon map 방정식에서는 $a=1.4, b=0.3$ 의 값을 가지 며, Henon map 방정식의 $a, b$ 값을 표준 값으로 설정 하면 그림 7과 같은 궤적을 그린다.

Henon map 궤적의 $\mathrm{x}$ 축은 $x_{n}$ 이고, $\mathrm{y}$ 축은 $y_{n}$ 이며, 2차원인 이산 시간의 동적 시스템이다. Henon map 은 $a$ 와 $b$ 라는 2 개의 매개변수를 가지고 있고, 이 매 개변수에 따라 궤적이 달라진다.

\section{2-3-4 Gauss Iterated Map}

$$
x_{n+1}=\exp \left(-\alpha x_{n}^{2}\right)+\beta
$$

Gauss iterated map의 방정식은 식 (8)로 표현되며, Gauss iterated map 방정식에서 $\alpha=4.8, \beta=-0.58$ 로 설정했을 때, 그림 8 과 같은 궤적을 그린다.

Gauss iterated map 궤적의 $\mathrm{x}$ 축은 $x_{n}$ 이며, $\mathrm{y}$ 축은 $x_{n+1}$ 이다. Gauss iterated map은 Gauss 함수에 의해 주어지는 연속시간에 따른 비선형적인 특징을 갖는 다. Tent map과 비슷한 궤적을 그리지만 Gauss iterated map은 종을 엎어놓은 모양의 궤적으로 나타난 다. 매개 변수 $\alpha=4.8, \beta=-0.58$ 일 때는 종의 일부분 만 그려지지만, 매개 변수 $\alpha$ 값을 변화시키면 완전한 종 모양을 그린다. 


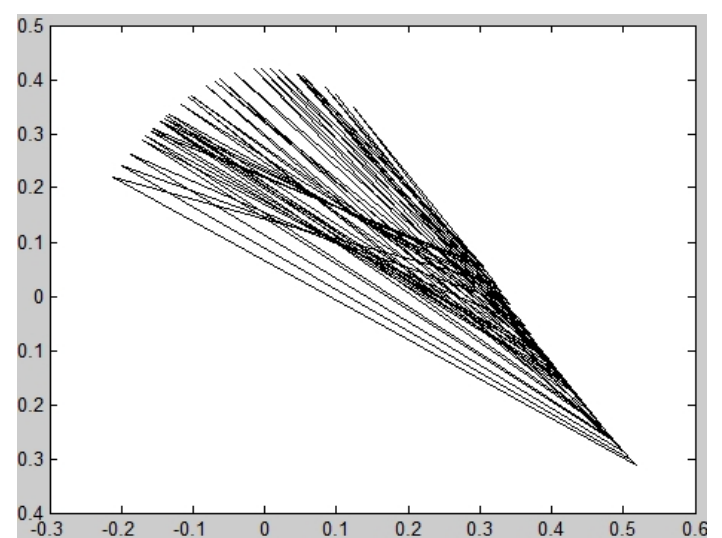

그림 8. Gauss iterated map의 궤적

Fig. 8. The trajectory of Gauss iterated map.

\section{III. 성능 평가}

이번 장은 DCSK 방식과 CDSK 방식에서 Tent map과 Logistic map, Henon map, Gauss iterated map에 따른 비트 에러율(Bit Error Rate: BER) 성능과 Gauss iterated map을 적용한 DCSK 방식과 CDSK 방식의 항재밍 특성을 평가한다.

\section{3-1 DCSK 방식에 적용된 Chaotic Map 성능}

\section{3-1-1 BER 성능 평가}

백색 가우시안 잡음(Additive White Gaussian Noise: AWGN) 환경에서 DCSK 방식에 Chaotic map을

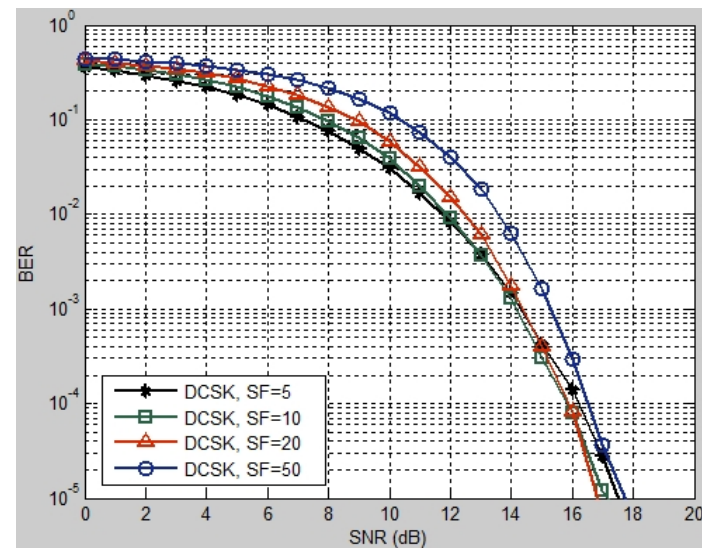

그림 9. 확산 인자에 따른 DCSK 방식의 BER 특성

Fig. 9. BER performance of DCSK system according to spreading factor.
적용한 카오스 변조 시스템의 성능은 적용한 Chaotic $\mathrm{map}$ 의 종류와 확산인자의 값에 따라서 달라진다.

그림 9는 DCSK 방식에서 확산 인자에 따른 BER 성능을 평가한 것이다. 그림 9 를 보면, 확산 인자가 많아지면 BER 성능이 저하되는 것을 알 수 있다. 즉, 그림 9 로부터 확산 인자의 증가함에 따라 큰 값의 확산 인자에서의 성능 열화를 볼 수 있다.

이 성능 열화는 잡음과 잡음 교차 항의 기여 증가 로 인해 발생하고, 송수신 신호의 상관 복호에 대해 서 일반적이다. 신호의 진폭을 고정하였을 때에 $E_{b} /$ $N_{0}$ 상수를 유지하기 위해 확산 인자를 증가시킴으 로써 $N_{0}$ 를 확산 인자에 비례적으로 증가시킨다. 그 렇기 때문에 확산 인자가 증가함에 따라 $N_{0}$ 가 증가 하기 때문에 BER 성능 열화가 발생하는 것이다 ${ }^{[11]}$.

Chaotic map을 적용한 DCSK 방식의 성능을 평가 하기 위하여 BER을 나타내는 식을 식 (9)로 정의 한다.

$$
B E R=\frac{1}{2} \operatorname{erfc}\left(\sqrt{\frac{E_{b}}{4 N_{0}}\left(1+\frac{2}{5 M}+\frac{N_{0}}{2 E_{b}} M\right)^{-1}}\right)_{(9)}
$$

식 (9)의 $M$ 은 마찬가지로 확산인자를 의미하며, 간섭이 존재하는 환경에서는 확산인자의 선택에 따 라 간섭의 영향이 달라지므로 이번 연구는 확산인자 를 50 으로 고정시켜 진행하였다.

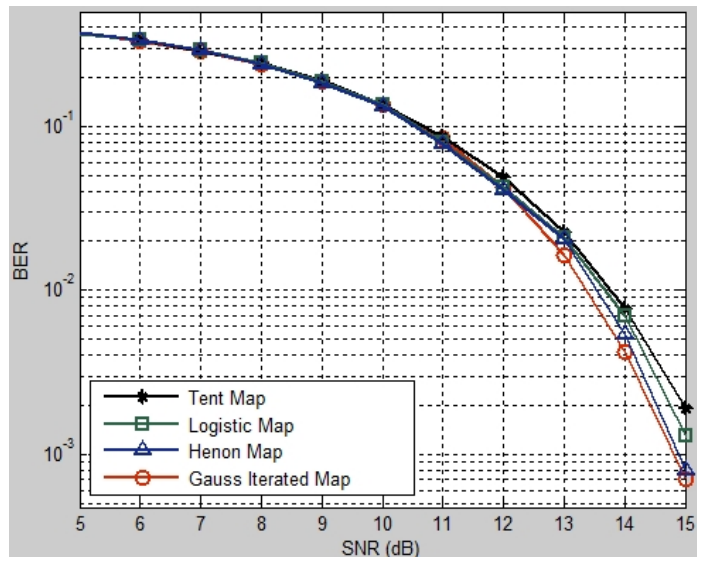

그림 10. Chaotic map에 따른 DCSK 방식의 BER 특성

Fig. 10. BER performance of DCSK system with different chaotic maps. 
그림 10은 Tent map과 Logistic map, Henon map, Gauss iterated map에 따른 DCSK 방식의 BER 성능 곡선을 나타낸 것이다 ${ }^{[13]}$. $\mathrm{BER}$ 이 $10^{-2}$ 일 때 각각의 Chaotic map을 비교해 보면 Henon map과 Gauss iterated map이 Tent map과 Logistic map보다 약 $0.5 \mathrm{~dB}$ 의 이득이 있음을 알 수 있다. 즉, 4 개의 Chaotic map 중에 Henon map이나 Gauss iterated map을 이용하면 좀 더 좋은 성능을 기대할 수 있으며, 둘 중에서는 Gauss iterated map을 DCSK 방식에 적용하는 것이 좀 더 효율적인 카오스 변조 시스템을 구축할 수 있다.

\section{3-1-2 항재밍 특성 평가}

Jamming이란 희망하는 신호 내용을 분명하지 않 게 하기 위해 별도의 전파를 발사하여, 희망하는 신 호의 수신을 고의로 방해하는 것을 의미하며, 흔히 방해 전파라고 한다. 즉, Jamming에 영향을 거의 받 지 않는 시스템은 그만큼 보안성이 높다는 것을 의 미한다. Jamming 유무에 따른 DCSK 방식의 BER 성 능 곡선을 알아보기 위해 Chaotic map의 종류 중 $\mathrm{BER}$ 성능이 좋은 Gauss iterated map을 DCSK 방식에 적용한다.

$$
S J R=\frac{\text { Signal Power }}{\text { Jammer Power }}
$$

신호대 재밍비(Signal-to-Jammer Ratio: SJR)는 식

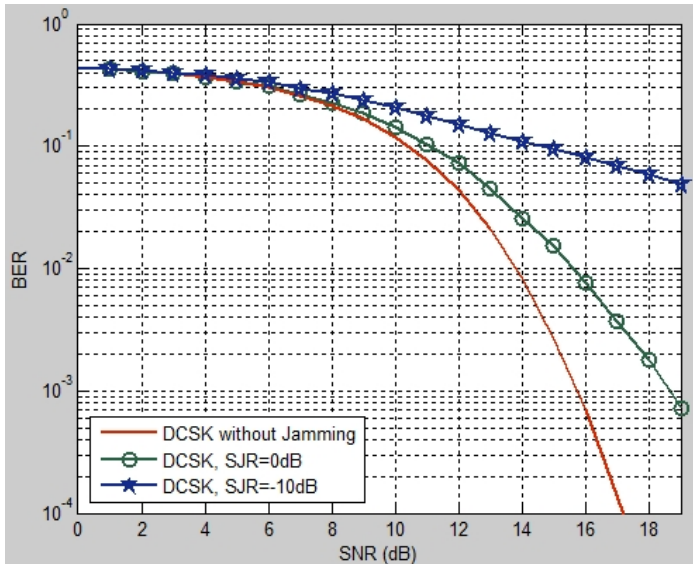

그림 11. SJR에 따른 DCSK 방식의 BER 특성

Fig. 11. BER performance of DCSK system according to SJR.

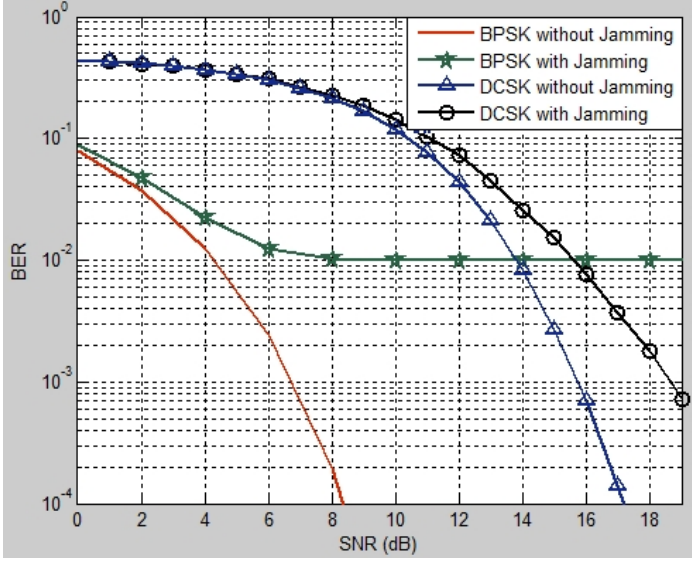

그림 12. Jamming 유무에 따른 BPSK 방식과 DCSK 방식의 BER 특성

Fig. 12. BER performance of BPSK and DCSK system according to Jamming.

(10)과 같이 표현할 수 있다.

그림 11 은 $\mathrm{SJR}$ 이 $0 \mathrm{~dB}$ 일 때와 $-10 \mathrm{~dB}$ 일 때의 $\mathrm{DC}$ $\mathrm{SK}$ 의 수신 BER 성능 곡선을 그린 것이다. Jamming 신호의 전력이 커짐에 따라서 수신 $\mathrm{BER}$ 성능이 열 화되는 것을 확인할 수 있다.

그림 12 는 $\mathrm{SJR}=0 \mathrm{~dB}$ 일 경우의 시뮬레이션 결과이 다. 시뮬레이션을 위해 전송 대역폭을 $50 \mathrm{MHz}$ 로, Jamming 신호의 대역폭을 $1 \mathrm{MHz}$ 로 가정하였다. Jamming의 유무에 따른 BPSK 방식과 Gauss iterated $\mathrm{map}$ 이 적용된 DCSK 방식의 BER 성능곡선을 비교 한 것이다. 그림 12 를 보면 Gauss iterated map이 적용 된 DCSK 방식이 BPSK 방식보다 항재밍 특성이 더 좋은 것을 알 수 있다.

이는 DCSK 변조 방식의 경우 확산인자에 의해서 신호가 확산되기 때문에 Jamming 신호에 BPSK 변 조에 비해 강한 특성을 보이는 것을 알 수 있다.

3-2 CDSK 방식에 적용된 Chaotic Map 성능

\section{3-2-1 BER 성능 평가}

CDSK 방식에 Chaotic map을 적용한 카오스 통신 시스템도 적용한 Chaotic map의 종류와 확산인자의 값에 따라서 달라진다.

그림 13을 보면, 신호대 잡음비(Signal to Noise Ra- 


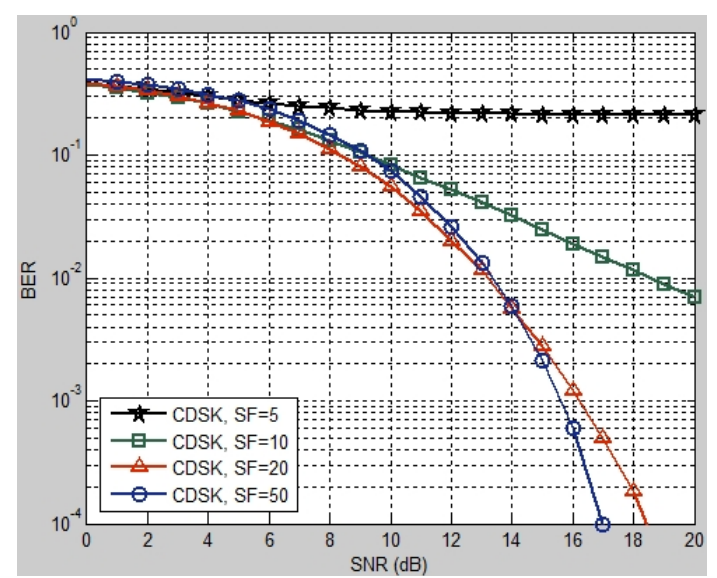

그림 13. 확산 인자에 따른 CDSK 방식의 BER 특성

Fig. 13. BER performance of CDSK system according to spreading factor.

tio: SNR)가 낮을 경우에는 BER 특성이 거의 비슷했 지만 SNR이 높은 경우에는 확산 인자가 많은 경우 의 $\mathrm{BER}$ 특성이 더 좋아지는 것을 알 수 있다.

Chaotic map을 적용한 CDSK 방식의 성능을 평가 하기 위하여 BER을 나타내는 식을 식 (11)로 정의 한다.

$B E R=\frac{1}{2} \operatorname{erfc}\left(\sqrt{\frac{E_{b}}{8 N_{0}}\left(1+\frac{19}{20 M}+\frac{N_{0}}{4 E_{b}} M\right)^{-1}}\right)$

식 (11)의 $M$ 은 확산인자를 의미하며, 간섭이 존재 하는 환경에서는 확산인자의 선택에 따라 간섭의 영

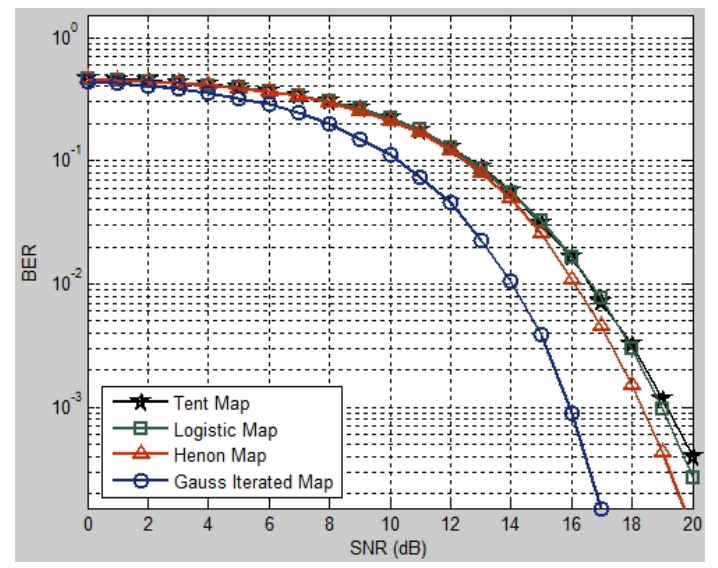

그림 14. Chaotic map에 따른 $\mathrm{CDSK}$ 방식의 $\mathrm{BER}$ 특성

Fig. 14. BER performance of CDSK system with different chaotic maps.

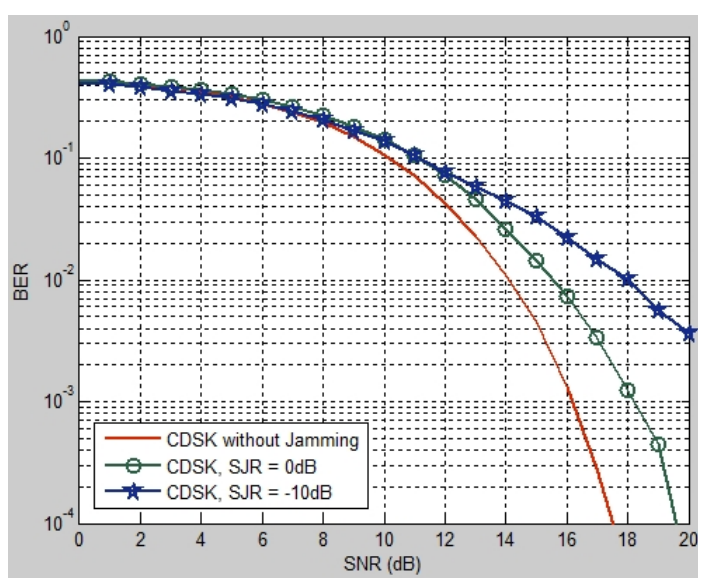

그림 15. SJR에 따른 $\mathrm{CDSK}$ 방식의 BER 특성

Fig. 15. BER performance of CDSK system according to SJR.

향이 달라지므로 $\operatorname{CDSK}$ 방식에서는 확산인자를 100 으로 고정시켜 진행하였다.

그림 14는 Tent map과 Logistic map, Henon map, Gauss iterated map에 따른 CDSK 방식의 BER 성능 곡선을 나타낸 것이다 ${ }^{[12]}$. $\mathrm{BER}$ 이 $10^{-3}$ 일 때 각각의 $\mathrm{Ch}-$ aotic map을 비교해 보면 Gauss iterated map이 Tent map과 Logistic map보다 약 $3 \mathrm{~dB}$ 의 이득이 있으며, Henon map보다 약 $2 \mathrm{~dB}$ 의 이득이 있음을 알 수 있 다. 즉, 4 개의 Chaotic map 중에 Gauss iterated map을 이용하면 좀 더 좋은 성능을 기대할 수 있다.

\section{3-2-2 항재밍 특성 평가}

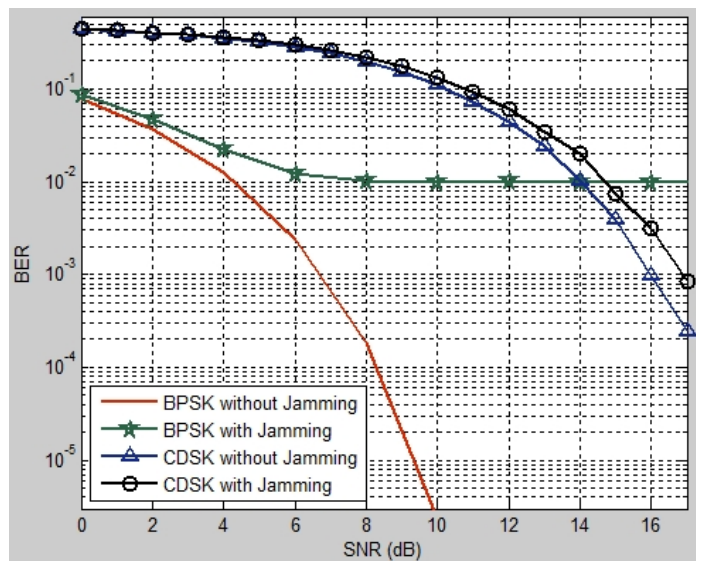

그림 16. Jamming 유무에 따른 BPSK 방식과 CDSK 방식의 $\mathrm{BER}$ 특성

Fig. 16. BER performance of BPSK and CDSK system according to Jamming. 
그림 15 는 $\mathrm{SJR}$ 이 $0 \mathrm{~dB}$ 일 때와 $-10 \mathrm{~dB}$ 일 때의 $\mathrm{BER}$ 성능 곡선을 그린 것이다. 그림 15 를 통해 $\mathrm{SJR}$ 이 감소할수록 항재밍 특성이 더 나빠지는 것을 알 수 있다.

그림 16은 Jamming의 유무에 따른 BPSK 방식과 Gauss iterated map이 적용된 CDSK 방식의 BER 성능 곡선을 비교한 것이다. 그림 16 을 보면 Gauss iterated map이 적용된 CDSK 방식이 BPSK 방식보다 항재밍 특성이 더 좋은 것을 알 수 있다.

\section{$\mathrm{NV}$. 결 론}

본 논문에서는 Chaotic map의 수많은 종류 중에서 Tent map과 Logistic map, Henon map, Gauss iterated map을 선택하여 4가지의 Chaotic map을 DCSK 방식 과 $\mathrm{CDSK}$ 방식에 적용하여 각각의 $\mathrm{BER}$ 성능을 비교 하고 항재밍 특성을 평가하였다.

4개의 Chaotic map에 따른 BER 성능을 비교해본 결과, DCSK 방식과 CDSK 방식 모두 Gauss iterated map을 적용한 카오스 통신 시스템의 BER 성능이 각 각 $0.5 \mathrm{~dB}, 2 \mathrm{~dB}$ 정도 더 좋게 평가되었다.

항재밍 특성을 평가한 결과 Chaotic map을 적용한 DCSK 방식과 CDSK 방식이 BPSK 방식보다 항재밍 특성이 더 좋게 평가되었으며, JSR이 증가함에 따라 항재밍 특성이 더 좋게 평가되었다.

정리하면, Chaotic map 종류 선택에 따라 효과적 인 BER 성능 개선을 이끌어낼 수 있으며, Chaotic map을 DCSK 방식과 $\mathrm{CDSK}$ 방식에 적용하는 것이 다른 사용자의 신호 감지를 어렵게 하며, 항재밍 특 성이 굉장히 좋다는 것을 확인할 수 있다.

\section{참 고 문 헌}

[1] Young Guen Seo, The World of Chaos, Dong-A University, vol. 29, pp. 520-524, 1989.

[2] N. F. Rulkov, M. M. Sushchik, "Digital communication using chaotic pulse position modulation", IEEE Trans. Circuits Syst., vol. 48, pp. 1436-1444, 2001.

[3] N. F. Rulkov, M. A. Vorontsov, and L. Illing, "Chaotic free-space laser communication over turbulent channel", Phys. Rev. Lett., vol. 89, pp. 277-905,
2002.

[4] Yongxiang Xia, C. K Tse, and F. C. M. Lau, "Performance of differential chaos-shift-keying digital communication systems over a multipath fading channel with delay spread", Circuits and Systems II: Express Briefs, IEEE Transactions on, vol. 51, no. 12, pp. 680-684, Dec. 2004.

[5] Yungil Kim, Jaehwan Kim, Jae-Hyon Kim, and Joonhyuk Kang, "Comparison of DCSK receiver and enhanced DCSK receiver with synchronization error", VTC 2006-spring IEEE 63rd., vol. 5, pp. 2261-2265, 2006.

[6] W. M. Tam, F. C. M. Lau, and C. K. Tse, "Generalized correlation-delay-shift-keying scheme for noncoherent chaos-based communication systems", Circuits and Systems I: Regular Papers, IEEE Transactions on, vol. 53, no. 3, pp. 712-721, Mar. 2006.

[7] Cem Sen, "Digital communications jamming", Master's thesis, Naval Postgraduate School, pp. 47-52, Sep. 2000.

[8] F. C. M. Lau, M. Ye, C. K. Tse, and S. F. Hau, "Anti-jamming performance of chaotic digital communication systems", Circuits and Systems I: Fundamental Theory and Applications, IEEE Transactions on, vol. 49, no. 10, pp. 1486-1494, Oct. 2002.

[9] W. Weisstein, Eric, "Logistic map", http:// mathworld.wolfram.com/LogisticMap.html, From MathWorld-A Wolfram Web Resource.

[10] W. Weisstein, Eric, "Henon map", http:// mathworld.wolfram.com/HenonMap.html, From MathWorld-A Wolfram Web Resource.

[11] Mikhail Sushchik, Lev S. Tsimring, and Alexander R. Volkovskii;, "Performance analysis of correlation-based communication schemes utilizing chaos", IEEE Transactions on, vol. 47, no. 12, Dec. 2000.

[12] Chan-Ho Jin, Heung-Gyoon Ryu, "Performance evaluation of chaotic CDSK modulation system with different chaotic maps", ICT Convergence (ICTC), 2012 International Conference on, pp. 603, 606, pp. 15-17, 2012. 
[13] Suwa Kim, Junyeong Bok, and Heung-Gyoon Ryu, "Performance evaluation of DCSK system with

이 준 현

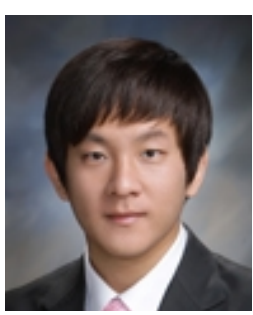

2013년 2월: 충북대학교 전자공학 과 (공학사)

2013년 3월 현재: 충북대학교 전자 공학과 석사과정

[주 관심분야] 보안 통신, 이동 통신 시스템 chaotic maps", International Conference On Information Networking(ICOIN), Jan. 2013.

유 흥 균

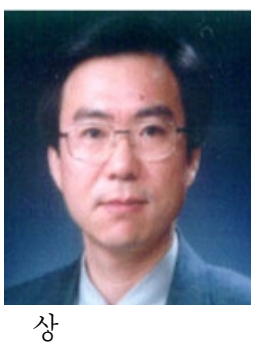

1988년 현재: 충북대학교 전자공 학과 교수

2002년 3월 2004년 2월: 충북대학 교 컴퓨터정보통신연구소 소장 1996년 현재: IEEE, IET 논문 심사 위원

2002년: 한국전자파학회 학술상 수 2008년: ICWMC 2008 국제학술대회 "Best Paper Award" 수상

2009년: SPACOMM 2009 국제학술대회 "Best Paper Award" 수상

[주 관심분야] 무선통신시스템, $\mathrm{B} 4 \mathrm{G} / 5 \mathrm{G}$ 이동통신 시스템, 위성통신, 통신회로 설계 및 통신 신호 처리 